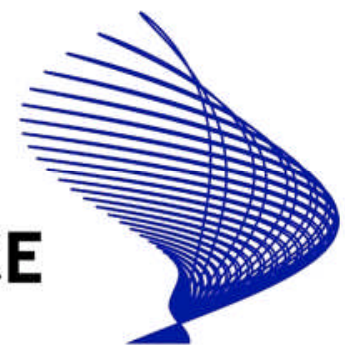

NORFACE MIGRATION Discussion Paper No. 2014-05

Do Migrants Send Remittances as a Way of Self-Insurance?

Evidence from a Representative Immigrant Survey

Catia Batista, Janis Umblijs 


\title{
Do Migrants Send Remittances as a Way of Self-Insurance? Evidence from a Representative Immigrant Survey ${ }^{\text {th }}$
}

\author{
Catia Batista ${ }^{1}$, Janis Umblijs ${ }^{2}$
}

(January 2014)

\begin{abstract}
Do migrants send remittances as a way of obtaining insurance? While this motive is theoretically suggested in the literature, the question of identifying this relationship empirically has only begun to be explored. Using a unique representative survey of 1500 immigrants in the Greater Dublin Area, Ireland, we find a positive and significant relationship between risk aversion and remittance behavior. Risk-averse individuals are more likely to send remittances home and are, on average, likely to remit a higher amount, after controlling for a broad range of individual and group characteristics. Consistent with a "purchase of self-insurance" motive to remit, we also provide evidence of more remittances sent by risk averse immigrants facing higher wage risks and remitting to individuals with more financial resources.
\end{abstract}

Keywords: Migration, Risk Aversion, Remittances, Insurance

JEL: D81, F22, F24, J01, J08, J15, J61

\footnotetext{
The authors gratefully acknowledge support from the Irish Research Council (IRC), Trinity College Dublin, and Nova Forum at the Nova School of Business and Economics. This paper is based on a representative immigrant survey generously funded by the EU NORFACE Programme on International Migration. We thank Pedro Pita Barros, Gaia Narciso, Pedro Vicente and participants in a number of seminars and international conferences for helpful comments

${ }^{1}$ Nova School of Business and Economics, Nova University of Lisbon, Portugal. CReAM, IZA and NOVAFRICA (catia.batista@novasbe.pt)

${ }^{2}$ Ragnar Frisch Centre for Economic Research, Oslo, Norway (janis.umblijs@frisch.uio.no).
} 


\section{Introduction}

The scale and growth of global remittance flows over the last decade has been unprecedented. Officially recorded remittances to developing countries have quadrupled over the last decade from US $\$ 85$ billion in 2000 to US $\$ 372$ billion in 2011 (Mohapatra et al., 2012; Silwa et al., 2010), a value three times greater than total official development assistance.

While this significant global flow of money has motivated a great deal of research, the reasons behind why people remit are still not fully understood. Several possible motives to remit have been identified in the literature, such as altruism (Agarwal and Horowitz, 2002), a sense of social responsibility and reciprocation to the network who covered the initial migration costs (Chort et al., 2012), income smoothing or insurance for households members in the origin country (Yang and Choi, 2007; Clarke and Wallsten, 2003; Paulson, 2000) or selfinsurance for migrants fearing uncertainty in the host country (Amuedo-Dorantes and Pozo, 2006). Understanding which motive dominates in any given context is crucial, as policies designed to support remittance flows by origin and host countries can only be effective if the motivation behind these financial flows is fully understood.

In this paper we investigate the extent to which the desire of migrants to self-insure against future risks they may face in the host country constitutes a motive to send remittances. There is evidence that networks at home often provide financial assistance to migrants in case of negative income shocks in the receiving country and that home networks are able to monitor the financial situation of the migrant through contacts with network members in the receiving country (Agarwal and Horowitz, 2002; De la Briere et al., 2002; Mazzucato, 2009). Given that the willingness of network members at home to provide financial assistance in difficult times is likely to depend on past remittances from the migrant, the decision to remit can be viewed as insurance against future negative shocks. While the self-insurance motive is sometimes mentioned, there are few studies that test this motive empirically - notable exceptions being Agarwal and Horowitz (2002); Lucas and Stark (1985); 
Amuedo-Dorantes and Pozo (2006).

The existing literature has mostly used two approaches to empirically test the selfinsurance motive to remit. The first strand of literature proposes that a positive relationship between income of migrant networks at home and migrant remittances is indicative of a selfinsurance motive to remit, while a negative relationship indicates altruism as the relevant remittance determinant. This would happen because migrants remitting with an insurance motive will increase the amount remitted when networks at home have larger income values and hence offer a larger insurance payoff - the underlying assumption being that the willingness of network members at home to provide financial assistance in difficult times is likely to depend on past remittances from the migrant and on the magnitude of their income flows. Alternatively, migrants will increase remittances in response to worsening economic situations in the home country when altruism is the dominant factor. Testing this theory empirically Lucas and Stark (1985) found that the insurance motive dominated, while Faini (1994) and Agarwal and Horowitz (2002) concluded that altruism was the main motive for remitting. The main drawback of this approach is that it focuses entirely on the remittance recipients and misses the variation in risk faced by the migrants themselves, which must have a significant impact on the demand for this type of insurance through the remittance channel.

An alternative way of testing for the insurance mechanism is to look at the wage risks that migrants face in the host country and how these relate to remittances. If migrants respond to increases in wage risk in the receiving country by remitting more, this may be interpreted as evidence of remittances as a way of purchasing self-insurance (against more likely future negative shocks affecting the migrant). Note, however, that if remittances were motivated by altruism, one would not be able to predict an obvious change in remittances - although altruistic motives may still be at play simultaneously with insurance motives. Amuedo-Dorantes and Pozo (2006) find evidence that Mexican migrants remit more when 
faced with higher wage risk, and are therefore driven, at least in part, by insurance motives. This approach has the advantages of being able to account for the wage risk faced by migrants in the host country using a number of proxy variables, and also of allowing for the possibility of both altruistic and insurance motives for remittances - a possibility not previously allowed in the literature. One limitation of the approach taken by Amuedo-Dorantes and Pozo (2006) is, however, the difficulty in ensuring that the proxy variables used for wage risk (such as legal status, educational attainment, time in the US, work experience, type of job and industry of employment) are not conflated with differences in migrant unobservable characteristics, such as risk attitudes, which can influence the demand for insurance.

This paper uses a unique representative data-set of 1500 immigrants in the Greater Dublin area, in Ireland, which includes detailed information not only on the characteristics of individual migrants and their networks both in the home and in the host countries, but also on migrant remittances, wage risks and risk preferences. With this information in hand, we build on the work of Amuedo-Dorantes and Pozo (2006) and use the established positive relationship between individual risk preferences and the purchase of insurance to investigate the existence of an insurance motive for sending remittances.

Our identification strategy rests first of all on the hypothesis that more risk-averse individuals have a preference for purchasing more insurance than less risk-averse individuals. In the migration context, this would translate into more risk averse migrants remitting more with the aim of self-insuring against potential negative outcomes. Therefore, a statistically significant positive link between risk aversion and money sent home would provide supportive evidence for the insurance motive.

To complement this novel empirical strategy using risk preferences as a source of variation in establishing self-insurance as a remittance motive, and in order to provide convincing evidence to support this motive, one needs to also account for other correlates with the insurance motive for remittances that were introduced in the past literature. Namely, we 
need to control for the income risk faced by the migrant in the host country (which will likely determine insurance demand), and also for the income variation faced by the migrant's network in the home country (which is a determinant of the expected insurance payoff). For this purpose, our empirical analysis uses proxies for the income risk that the individual migrant faces in the host country, and also for the income variation in his network at home. In this context, we expect the relationship between risk aversion and remittances to be stronger for individuals facing higher wage risk and remitting for insurance motives, and not meaningful for those not facing wage risk and remitting for other motives such as altruism. The inclusion of information on individual risk preferences to the empirical strategy followed by Amuedo-Dorantes and Pozo (2006) should help to control for some of the unobserved heterogeneity potentially present in previous work, in addition to also providing a direct test of the insurance motive for migrant remittances.

The information in our dataset also allows us to control for other potential determinants of remittance behavior that could be confounded with the insurance motive - namely asset accumulation. Following Amuedo-Dorantes and Pozo (2006), this form of savings can be interpreted as self-insurance provided directly by the migrants, in addition (or as an alternative) to any self-insurance that migrants are purchasing from their networks as a counterpart for remittances sent.

Overall, we find that there is a statistically significant positive relationship between being risk averse and both the probability to remit and the amount remitted by migrants. This result remains significant after including a wide range of controls suggested by the existing literature. Furthermore, we find that the relationship between risk aversion and remittances is especially significant for individuals with temporary contracts, those expressing an intention to return and those with working network members in the sending country - a variety of robustness checks that strengthens the support for a self-insurance remittance motive. While we do not exclude other motives to remit, such as altruism or insurance for those 
who stayed behind, it seems clear that migrants do remit with the purpose of self-insuring against uncertainty faced in the host country.

The rest of the article is organized in the following way: section 2 describes the survey design and presents descriptive statistics; section 3 introduces the empirical strategy, while sections 4 and 5 present and discuss the results; finally, section 6 concludes.

\section{Data and Descriptive Statistics}

\subsection{Background on Survey}

This paper uses a tailored representative household survey of the immigrant population in the Greater Dublin Area. The survey was conducted among 1500 immigrants aged 18 years or older, residing in the Greater Dublin Area, who arrived in Ireland between ten years and six months prior to the interview date, and who were not Irish or British citizens. Eligibility requirements were set to maximize the probability that migrants still kept contacts outside of Ireland but were already minimally established in Ireland so that contacts with their networks abroad could provide useful information.

The survey was conducted between February 2010 and December 2011 by Amarach Research, a reputable survey company with prior experience in conducting research surveys in Ireland, under close supervision of the research team.

The sample of immigrants in our survey is representative of the total immigrant population, both registered and non-registered, in the Greater Dublin Area. In order to perform random sampling, 100 Electoral Districts (EDs) were randomly selected out of the 323 EDs in the Greater Dublin Area. This selection was performed according to probabilityproportional-to-size sampling, in which size is defined as the total number of non-Irish and non-British individuals residing in Ireland, according to the 2006 Census of Ireland. After the first randomization level of ED selection, 15 households were selected within each ED using a random route approach, starting at initial addresses within each ED that were also selected randomly. Furthermore, in the presence of more than one eligible respondent in the 
household, the individual respondent within each household was selected randomly based on a next-birthday rule. In the absence of the designated respondent, an appointment was set up for a later date.

All enumerators were initially trained by the research team and were subsequently supervised by the survey company and, randomly, by members of the research team. Each enumerator had to complete an enumeration report, listing each address approached, the number of call-backs and the outcome of each visit ${ }^{3}$. The enumeration reports were closely inspected and verified by the research team. If the randomization instructions were not followed, interviews had to be replaced.

When selected respondents declined to be interviewed, their characteristics (namely gender, approximate age, nationality and type of dwelling) were recorded to allow for the adjustment of sampling weights. The final data was weighted by nationality, age and gender of non-respondents. According to the enumeration records, on average, the interviewers had to approach around 100 addresses to obtain one completed interview.

The design of the survey questions and the data collection strategy were carefully developed in order to ensure that our sample is representative of all migrants, including illegal and non-registered migrants. The randomized procedure for selecting addresses within an ED was useful in capturing a representative selection of migrants, including those that were not registered in official data. The legal status of respondents was not asked and this was made clear to the respondents before the survey was administered. In addition, it was made clear to respondents that the data would be anonymized and not used for any purposes other than academic research. In order to maximize trust, interviewers were chosen from a broad range of backgrounds and received detailed classroom and in-the-field training, followed up

\footnotetext{
${ }^{3}$ Non-responses, due to no one being at home at the time of the visit, were minimized by interviewers going back to an address up to 5 times on different days and at different times. While this 5 times 'call back' rule was time consuming, it ensured that non-response was minimized and that a representative sample of migrants was selected, including single dwelling households which would otherwise be under represented.
} 
by randomized quality checks.

Obtaining a representative sample of migrants is important in the context of our research as it avoids sample selection problems which are present in related work where data collection methodologies include surveys conducted in the border regions of sending countries (AmuedoDorantes and Pozo, 2006), or generally limited to return migrants and family members left in the home country (Agarwal and Horowitz, 2002; Lucas and Stark, 1985).

In order to measure risk preferences in the domain of money, we use a hypothetical lottery question. This measure has been used by a number of studies in the literature, ${ }^{4}$ and has been validated using real monetary payments (Dohmen et al., 2005). Our survey also includes a number of questions regarding remittances to encompass all channels that could be used to transfer money or gifts to individuals in the sending country. The survey allowed for the possibility of money transfers, money handed over in person (in Ireland or in the sending country) and gifts sent or given in person. The survey also included questions on the frequency and amount remitted and the cost of sending money and gifts home. In addition, data on the characteristics of individuals that receive remittances, including age, gender, country of residence and relationship to the respondent are available. Batista and Narciso (2013) and Batista and Umblijs (2013) present complementary analysis of the same migrant survey focusing on questions related to the importance of asymmetric information in transnational networks in determining remittance flows, and the role of risk attitudes for migrant entrepreneurship.

\subsection{Descriptive Statistics}

Our sample is made up of migrants from a broad range of countries. The three most popular origin countries are Nigeria, Poland and India. All other country groups consist of less than $5 \%$ of the sample. Other European Union 'New Member States' are also represen-

\footnotetext{
${ }^{4}$ See for example, Van Praag and Cramer (2001); Ahn (2010); Bonin et al. (2007); Zimmermann et al. (2009); Caliendo et al. (2009, 2010); Niimi et al. (2009)
} 
ted, with the largest groups being Romanians, Lithuanians, and Latvians. The two largest migrant groups in Greater Dublin by world Region of Birth are Africa and Asia.

Our measure of willingness to take risks is based on a hypothetical lottery question as shown in Figure 1. The results from the question range from 0 (corresponding to no lottery purchase) to 10 (corresponding to spending all available 100,000 Euros in a risky lottery). Figure 2 shows the distribution of responses to the hypothetical lottery question. According to Figure 2, the most common answer to the hypothetical lottery question was not to gamble any of the money, while the other responses approximate a normal distribution with mean at gambling $60 \%$ of the available amount.

From our sample of migrants, $36 \%$ sent money home at least once in the year preceding the interview. From those that did send money home, the amount varied significantly as shown in Figure 3, ranging from EUR 3 to EUR 10,000.

There is a substantial variety in the probability of remitting between world regions of birth. As shown in Table 1, migrants from Africa are the most likely to remit with $40 \%$ sending some money home, migrants from Asia are the second most likely to remit (36\% do so in our sample). While $31 \%$ of the New EU Member State migrants remit money home, only $7 \%$ of pre-2004 enlargement EU states send remittances home.

Regarding the relationship between risk aversion and the probability of remitting, a simple comparison of averages for the total sample shows that a larger proportion of risk averse individuals send remittances compared to risk loving individuals. Table 2 shows that, while only $27 \%$ of risk loving individuals sent remittances, $40 \%$ of risk averse migrants sent money to networks in the source country.

\section{Empirical Methodology}

The empirical relationship between risk aversion and remittances can be summarized as follows: 


$$
\text { Remittances }_{i}=\beta_{1} \text { Risk Preference }+\beta_{2} \text { Individual Controls }+\epsilon_{i}
$$

This expression describes how migrant remittances vary with risk aversion, while controlling for an array of individual characteristics that are correlated with a migrant's willingness and capacity to remit. These controls include basic demographics, such as gender, age, years of schooling, religion, marital status, having children, industry of occupation, income, financial distress indicators, and world region of origin. In addition, our specification includes controls for likely determinants of the willingness to self-insure through remittances: namely income risk faced by the migrant in the host country (proxied by employment contract duration) and proxies for the likelihood to return home (such as the reported intention to return, number of years in Ireland, partner living in Ireland and Irish partner), which are both correlated with the likelihood of requesting financial assistance upon return home, and hence determine insurance demand. We also include as a control income variation faced by the migrant's network in the home country (proxied by employment status of the network member, an indicator of financial resource availability), which may be interpreted as a determinant of the expected insurance payoff. Finally, we also control for the presence of migrant savings, which can be interpreted as self-insurance provided directly by the migrants, in addition (or as an alternative) to any self-insurance that migrants are purchasing from their networks as a counterpart for remittances sent.

We estimate different specifications of this econometric model. We start by estimating a model for the extensive margin of remittances (i.e. the migrant's decision of whether to remit or not). For this purpose, we run a Probit model where the dependent variable is a binary variable taking the value of 1 when the individual migrant sent any form of remittances in the year before the survey, and we include all controls described above. In additional specifications, we also add interaction terms for risk preferences and contract duration, intention to return and employment status of network members in order to provide 
a strict test of the "self-insurance purchase" motive for remittances. This is because one would expect that risk averse migrants will seek additional insurance when they face a larger likelihood of needing to request financial assistance from their networks and also when they perceive greater financial availability in their networks at home.

More precisely, we use the following general Probit specification :

$$
\operatorname{Pr}\left(Y_{i}=1 \mid \mathbf{X}_{\mathbf{i}}\right)=\Phi\left(\beta_{1} x_{i 1}+\beta_{2} x_{i 2}+\beta_{12} x_{i 1} x_{i 2}+\mathbf{X}_{\mathbf{i}} \beta\right)+\epsilon_{i}
$$

where $Y_{i}$ is a binary variable taking value 1 when individual $i$ sent any remittances to anyone in his network in the home country in the last year; $\beta_{1}$ is the coefficient on the variable summarizing risk aversion $x_{i 1} x_{i 2}$ is a dummy variable for the type of contract, intention to return or employment status of network member; and $\beta_{12}$ is the interaction effect. $\mathbf{X}_{\mathbf{i}}$ is the vector of control variables described previously, which are likely correlated with remittance behavior.

We are also interested in the amount of remittances sent, the intensive margin, and use a zero censored Tobit model to account for the significant proportion of individuals that have not sent any remittances in the year prior to the survey. There are a number of alternative solutions to the issue of zero censoring in remittance data. (Bettin et al., 2012) suggest double hurdle and Heckit models to account for the possibility of different mechanisms influencing the decision to remit and the amount to be remitted. While this has the advantage of accounting for non-remittance due to budgetary constraints, this type of model can be sensitive to identification exclusions. This is especially a problem for data on remittances, as finding realistic variables that affect the decision to remit money, but not the amount, are difficult to conceive of (Amuedo-Dorantes and Pozo, 2006). Therefore, we opt for the Tobit model, which accounts for the zero censoring without the identification issues of the selection models. More specifically our econometric specification is: 


$$
\begin{gathered}
Y_{i}^{*}=\beta_{1} x_{i 1}+\beta_{2} x_{i 2}+\beta_{12} x_{i 1} x_{i 2}+\mathbf{X}_{\mathbf{i}}^{\prime} \beta+\epsilon_{i} \\
Y_{i}=\max \left(0, Y_{i}^{*}\right) \\
\epsilon_{i} \sim N\left(0, \sigma^{2}\right)
\end{gathered}
$$

where the latent variable $Y_{i}^{*}$ is modeled as depending on the same independent variables as those included in the Probit model outlined in (5), and the dependent variable $Y_{i}$ is the zero censored amount remitted in Euros in the last year.

\section{Empirical Results}

\section{Risk Aversion and Remittances}

Table 3 presents estimates for the relationship between risk aversion and remittances both at the extensive and intensive margin. Column (1) of Table 3 suggests that there is a significant positive relationship between risk aversion and the probability of remitting: being risk averse (according to this definition) corresponds to a 19\% point increase in the probability of remitting after controlling for a large range of variables.

These controls include short contract duration (as a proxy for wage risk in the host country) and the intention to return (as a proxy for the likelihood of needing to use insurance upon return). According to the existing literature, both these variables should correlate positively with the demand for self-insurance via remittances. We indeed obtain positive coefficients but they are not precisely estimated when we account for individual risk aversion. We also control for savings, which could be regarded as an alternative way for migrants to obtain self-insurance. This coefficient shows, however, positively in our estimation, although not very precisely estimated, which may indicate that savings are a complementary to remittances as a way for migrants to obtain self-insurance. 
These controls include short contract duration (as a proxy for wage risk in the host country) and the intention to return (as a proxy for the likelihood of needing to use insurance upon return). According to the existing literature, both these variables should correlate positively with the demand for self-insurance via remittances. We indeed obtain positive coefficients but they are not precisely estimated when we account for individual risk aversion. We also control for savings, which could be regarded as an alternative way for migrants to obtain self-insurance. This coefficient shows, however, positively in our estimation, although not very precisely estimated, which may indicate that savings are a complementary to remittances as a way for migrants to obtain self-insurance.

In terms of the intensive margin (i.e. using the amount remitted as dependent variable), column (2) in Table 3 shows that being risk averse is associated with an average increase of EUR 945 in the amount remitted in the previous year.

Note that the dummy variable 'Risk Averse', as used in columns (1) and (2) of Table 3, is defined as investing less than EUR 10,000 in the hypothetical lottery and corresponds to approximately $50 \%$ of the responses in our sample of migrants. Columns (3) to (6) of Table 3 show that the relationship between risk aversion and remittances keeps holding positive and significantly when risk version is defined as investing less than EUR 20,000 (Risk Aversion alternative 1) or EUR 5,000 (Risk Aversion alternative 2) in the hypothetical lottery.

\section{Income Risk and Remittances}

Table 4 shows how the probability of remitting correlates with temporary employment contracts, with duration of less than one year - a proxy for wage risk faced by migrants. The reference group is given by individuals with permanent employment contracts. Results are shown for when temporary is interacted with the risk aversion dummy. The results in Column (1) of Table 4 suggest that the relationship between having a temporary contract and the probability of sending remittances is especially significant for risk averse individuals. Column (2) in Table 4 focuses on the intensive margin. The results suggest that while having 
a temporary contract is associated with remitting less relative to the control group, being risk averse and having a temporary contract is associated with sending more remittances.

This evidence strengthens our hypothesis that, when facing additional income risk in the host country, risk averse individuals will remit more in an attempt to purchase additional self-insurance from their network members at the origin.

Table 5 investigates the relationship between intention to return and remittances, including risk aversion interaction terms. Column (1) in Table 5 shows that expressing an intention to return while being risk averse is associated with an increased probability of remitting whereas this effect is not significant for the risk loving reference group. Looking at the intensive margin, the results in column (2) of Table 5 suggest that having an intention to return and being risk averse is associated with a higher amount being remitted, while the return intention without interaction seems to be negatively correlated with the amount remitted.

These results show that remittances sent by risk averse migrants are increasing with the likelihood of returning to the origin country and benefiting from any "insurance" the migrant has purchased with remittances.

\section{Status of Network Members and Remittances}

As well as the relationship of the remittance recipient to the migrant, the financial situation of the home network also plays a role in the decision to send money home as a method of self-insurance. Migrants wanting to insure themselves via remittances do so with the expectation of receiving financial assistance from home network members in case of a negative outcome in the future, making the financial situation of contacts at home an important consideration. Sending remittances will only function as an insurance mechanism if the migrant believes that the network member at home is in a position to provide financial assistance when required. Therefore, the insurance motive is likely to dominate when home network members have more resources, while altruism usually dominates when networks are less fin- 
ancially stable. We test this hypothesis by utilizing information on the employment status of network members. In our sample $67 \%$ of network members are currently employed and we would expect the insurance motive to be stronger for migrants sending remittances to this group compared to those with network members not working.

Table 6 shows the results of the intensive and extensive margin for the employment situation of the remittance recipient. Column (1) of Table 6 suggests that there is a positive link between having an employed network member and being risk averse. Similar results can be seen for the intensive margin, where there is a (marginally) significant positive link between having an employed network member and being risk averse.

This evidence lends some support to the hypothesis that migrants target network members with good economic status to purchase self-insurance by sending remittances to these "well-off" network members.

\section{Outside Family Networks and Remittances}

It is likely that altruistic motives dominate for remittances to immediate family (such as parents, children or spouses). This proposition would imply that remitting to a network contact outside the immediate family is therefore relatively more likely to follow the selfinsurance motive for remittances. We test this implication, by examining the remittance impact of having a main network contact outside of the immediate family.

The results confirm that having a main network contact outside of the immediate family is associated with a lower probability of sending remittances as well as remitting a lower amount in the year prior to the survey, as shown by Table 7 Columns (1) to (3). However, when we investigate the interaction term for being risk averse and remitting outside of the immediate family, the results support our hypothesis that more self-insurance motivated remittances are sent to the network members outside of the immediate family, as can be seen in Table 7, Columns (2) and (5).

We also investigate the triple interaction of the migrant being risk averse, having a main 
network member outside the family and that network member having a stable employment situation. As we would expect, the sign of this triple interaction is positive suggesting that for remittances sent outside the household by risk averse individuals, a stable employment status of the network member is valuable and positively associated with remittances at the extensive and intensive margin, as can be seen in Table 7, Columns (3) and (6).

\section{Discussion of Results}

Our results suggest that there is a positive relationship between risk aversion and remittances. Given that we control for individual key characteristics, this measure is a good proxy for the inherent risk preference of individuals in the domain of money. In addition, this type of risk measure has been validated using real monetary incentives for the German Socioeconomic Panel study by Dohmen et al. (2005), which lends confidence that this hypothetical question is able to capture actual risk attitudes in the domain of money of the individuals in our survey.

We are also able to test the relationship between wage risk and remittances. As in Amuedo-Dorantes and Pozo (2006) we also found evidence that migrants on temporary contracts are more likely to remit than those with permanent contracts. However we include an additional test to support the suggestion that the link between wage risk and remittances is due to the insurance motive by interacting the contract type variables with our risk preference variable. As suggested by our hypothesis, we find that having a non-permanent contract is only significantly related to remittances for the risk averse individuals in our sample.

Given that migrants who intend to return are more likely to benefit from the support of network members after return, we also investigated the link between intention to return and the probability of remitting. While we find no strong significant link between the intention to return and remittances in general, we do find a significant positive link for this relationship for risk averse individuals. This corresponds to the insurance motive for remittances as risk 
averse individuals have a stronger preference to purchase insurance, and these risk averse individuals with an intention to return have a higher incentive to remit for insurance purposes as they are most likely to benefit from this insurance.

We also look at the relationship between the employment status of the network member and remittances. We expect that employed network members are more likely to have the resources to assist migrants in case of difficulty and are therefore more likely targets of remittances sent with the purpose of self-insurance. We find that while risk loving migrants are less likely to send remittances if network members are employed, risk averse averse migrants are more likely to send remittances if network members are employed. This supports the hypothesis that risk averse migrants have a higher preference for insurance and therefore remit more when networks have a more stable situation. Risk loving individuals have a lower preference for insurance and are more likely to remit for other motives such as altruism, in which case we would expect a negative link between the financial resources of the network and remittances.

\section{Conclusions}

The relationship between risk aversion and remittance behavior was tested using a representative household survey of the immigrant population in the Greater Dublin Area, in Ireland. We find a statistically significant positive relationship between immigrant risk aversion and both the probability to remit and the amount remitted by individuals in our sample.

The results suggest that being risk averse is associated with an increase in the probability of remitting of nearly 20 percentage points, and an increase in the amount remitted of nearly EUR 1000 per year. Examining specific groups in our sample we find that migrants on temporary contracts, those expressing an intention to return and those with employed network members are more likely to remit, the more risk averse they are. This relationship is robust to different specifications.

Our results support the hypothesis of a self-insurance motive for remittances. The use of 
an individual risk aversion variable allowed us to investigate this hypothesis in a novel way, accounting for relevant unobservable characteristics of immigrants, while strengthening the case already made in support of this hypothesis in previous literature. This is an important finding for policy-making in a world where the magnitude and importance of remittance flows particularly for developing countries keeps growing. 


\section{References}

Agarwal, R., Horowitz, A., 2002. Are international remittances altruism or insurance? Evidence from Guyana using multiple-migrant households. World Development 30 (11), 20332044.

Ahn, T., 2010. Attitudes toward risk and self-employment of young workers. Labour Economics 17 (2), 434-442.

Amuedo-Dorantes, C., Pozo, S., 2006. Remittances as insurance: evidence from Mexican immigrants. Journal of Population Economics 19 (2), 227-254.

Batista, C., Narciso, G., 2013. Migrant remittances and information flows: Evidence from a field experiment. IZA Discussion Paper 7839.

Batista, C., Umblijs, J., 2013. Migration, risk attitudes, and entrepreneurship: Evidence from a representative immigrant survey. IZA Discussion Paper 7781.

Bettin, G., Lucchetti, R., Zazzaro, A., 2012. Endogeneity and sample selection in a model for remittances. Journal of Development Economics 99 (2), 370-384.

Bonin, H., Dohmen, T., Falk, A., Huffman, D., Sunde, U., 2007. Cross-sectional earnings risk and occupational sorting: The role of risk attitudes. Labour Economics 14 (6), 926 937.

Caliendo, M., Fossen, F., Kritikos, A., 2009. Risk attitudes of nascent entrepreneurs. New evidence from an experimentally validated survey. Small Business Economics 32 (2), 153167.

Caliendo, M., Fossen, F., Kritikos, A., 2010. The impact of risk attitudes on entrepreneurial survival. Journal of Economic Behavior \& Organization 76 (1), 45-63. 
Chort, I., Gubert, F., Senne, J.-N., 2012. Migrant networks as a basis for social control: Remittance incentives among senegalese in france and italy. Regional Science and Urban Economics $42(5), 858-874$.

Clarke, G., Wallsten, S., 2003. Do remittances act like insurance? Evidence from a natural disaster in Jamaica. Development Research Group, The World Bank.

De la Briere, B., Sadoulet, E., De Janvry, A., Lambert, S., 2002. The roles of destination, gender, and household composition in explaining remittances: an analysis for the Dominican Sierra. Journal of Development Economics 68 (2), 309-328.

Dohmen, T., Falk, A., Huffman, D., Schupp, J., Sunde, U., Wagner, G., 2005. Individual risk attitudes, new evidence from a large, representative, experimentally-validated survey. IZA Discussion Papers 1730.

Faini, R., 1994. Workers remittances and the real exchange rate. Journal of Population Economics 7 (2), 235-245.

Lucas, R., Stark, O., 1985. Motivations to remit: Evidence from Botswana. The Journal of Political Economy, 901-918.

Mazzucato, V., 2009. Informal insurance arrangements in ghanaian migrants transnational networks: The role of reverse remittances and geographic proximity. World Development 37 (6), 1105-1115.

Mohapatra, S., Joseph, G., Ratha, D., 2012. Remittances and natural disasters: ex-post response and contribution to ex-ante preparedness. Environment, Development and Sustainability, 1-23.

Niimi, Y., Pham, T., Reilly, B., 2009. Determinants of Remittances: Recent Evidence Using Data on Internal Migrants in Vietnam. Asian Economic Journal 23 (1), 19-39. 
Paulson, A. L., 2000. Insurance Motives for Migration: Evidence from Thailand. Manuscript, Kellogg Graduate School of Management, Northwestern University.

Silwa, A., Ratha, D., Mohapatra, S., 2010. Outlook for remittance flows 2011-12: Recovery after the crisis, but risks lie ahead. World Bank, Washington, DC.

Van Praag, C., Cramer, J., 2001. The roots of entrepreneurship and labour demand: Individual ability and low risk aversion. Economica 68 (269), 45-62.

Yang, D., Choi, H., 2007. Are remittances insurance? Evidence from rainfall shocks in the Philippines. The World Bank Economic Review 21 (2), 219-248.

Zimmermann, K., Bonin, H., Constant, A., Tatsiramos, K., 2009. Native-migrant differences in risk attitudes. Applied Economics Letters 16, 1581-1586. 


\section{Tables and Figures}

Figure 1: Survey Question

\section{LOTTERY QUESTION}

Finally, please consider what you would do in the following situation.

Imagine that you had won 100,000 Euros in the lottery.

Almost immediately after you collect the winnings, you receive the following financial offer from a reputable bank, the conditions of which are as follows: There is the chance to double the money within two years.

It is equally possible that you could lose half of the amount invested within two years.

You have the opportunity to invest the full amount, part of the amount or reject the offer.

L014: What share of your lottery winnings would you be prepared to invest in this financially risky, yet lucrative investment?

\begin{tabular}{|l|l|}
\hline Nothing, I would decline the offer & 0 \\
\hline 100 Euros & 1 \\
\hline 500 Euros & 2 \\
\hline 1,000 Euros & 3 \\
\hline 5,000 Euros & 4 \\
\hline 10,000 Euros & 5 \\
\hline 20.000 Euros & 6 \\
\hline 40.000 Euros & 7 \\
\hline 60,000 Euros & 8 \\
\hline 80,000 Euros & 9 \\
\hline All 100,000 Euros & 10 \\
\hline Missing [Note: Do not read the Missing.] & 99 \\
\hline
\end{tabular}


Figure 2: Risk Preferences Among Migrant Sample

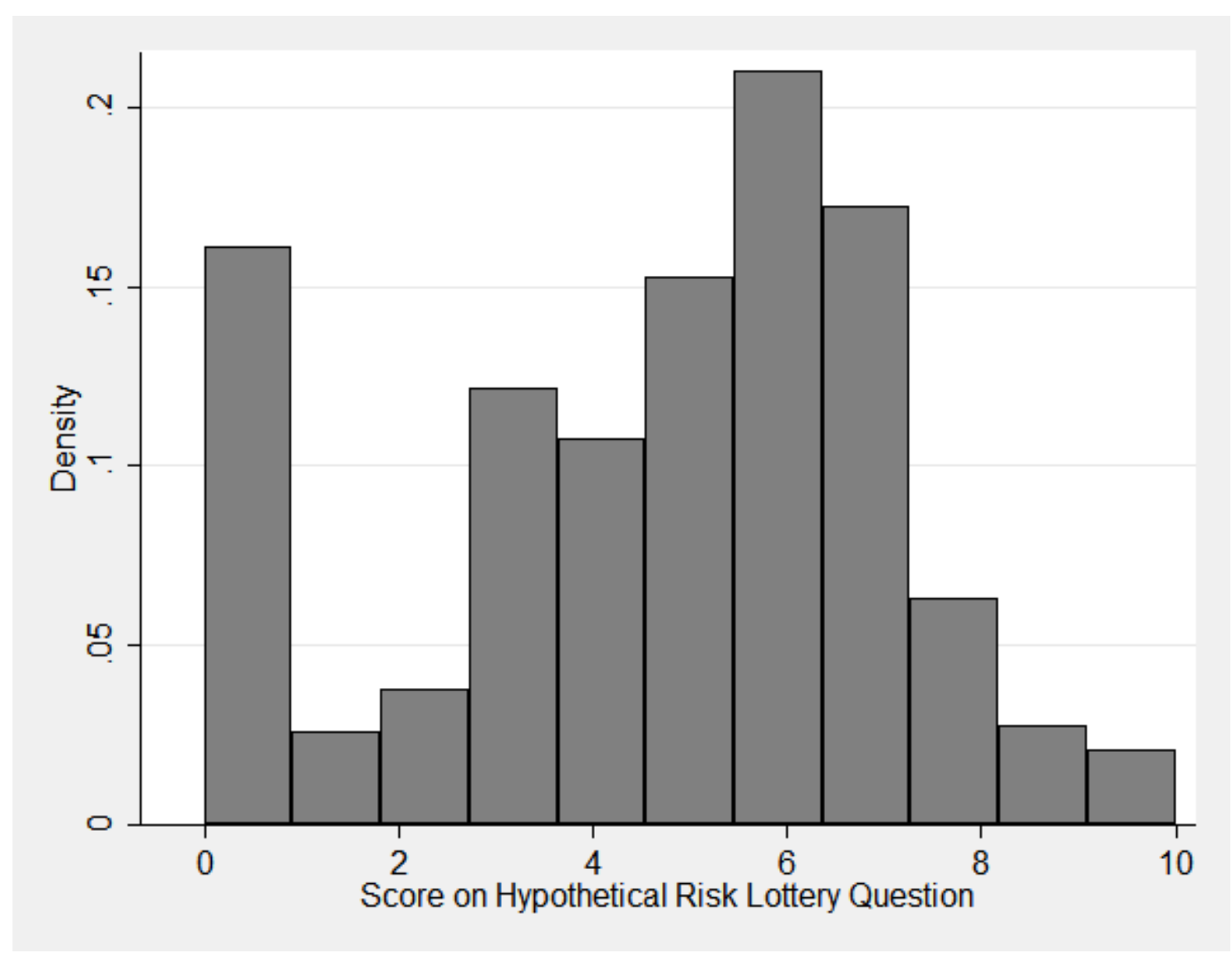

Note: The Table shows the density distribution of risk preferences among migrants. The numbers scored reflect the answer to a hypothetical lottery question. The scale of the responses ranges from 0 to 10 with 10 corresponding to the highest willingness to take risks. 
Figure 3: Amount of Remittances Sent Home in the Previous Year (EUR)

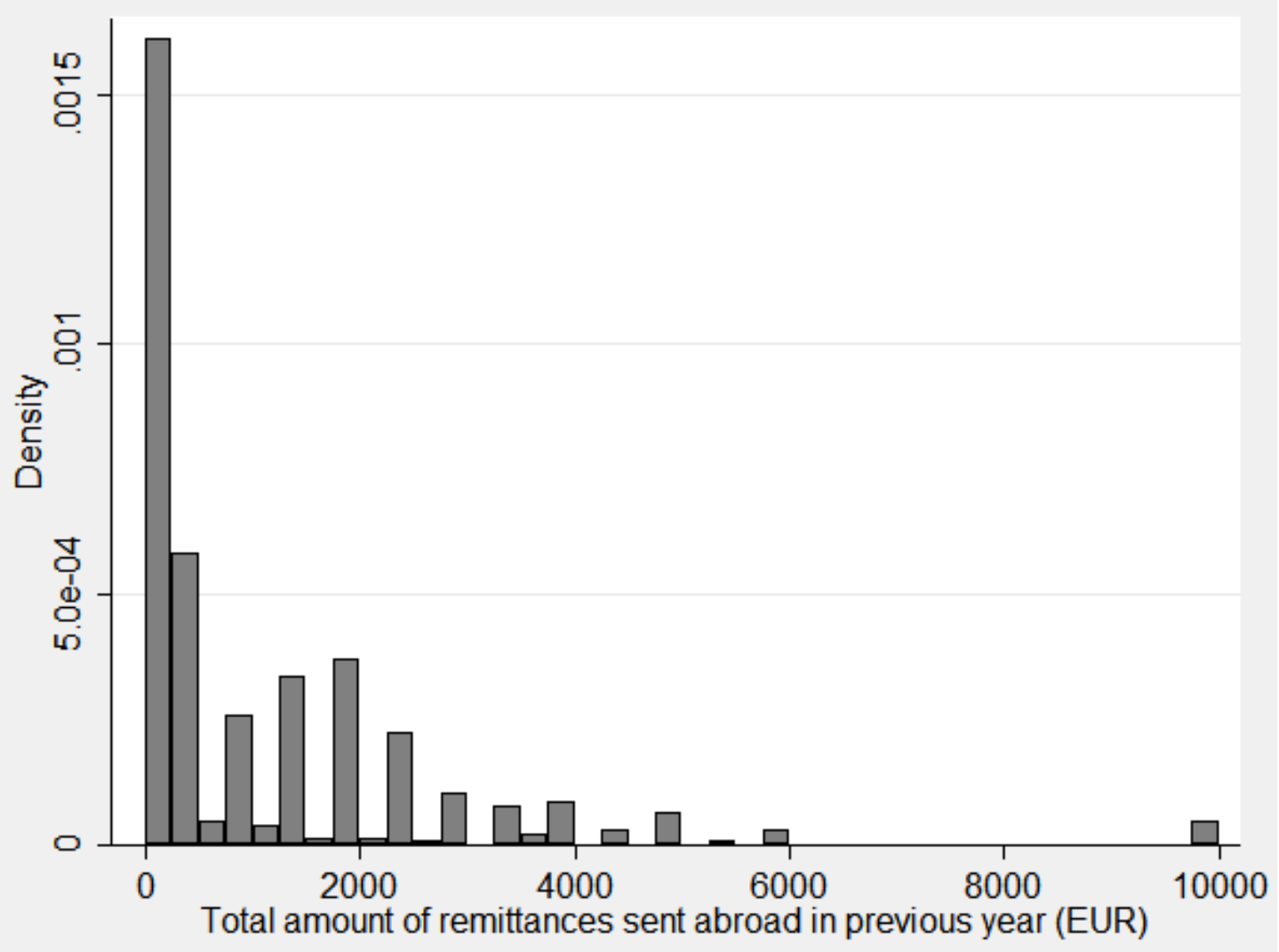

Note: The Table shows the density distribution of remittances sent in the last year by migrants in Euros. The graph represents the $36 \%$ of respondents that sent at least some remittances in the previous year. 
Table 1: Percentage of Migrants Remitting by Region of Birth

\begin{tabular}{cc}
\hline Region & Percent remit (\%) \\
\hline Africa & 40 \\
Asia & 36 \\
EU(NMS) & 31 \\
South America & 19 \\
North America & 12 \\
EU(OMS) & 7 \\
\hline All Average & $\mathbf{3 3}$ \\
\hline
\end{tabular}

Note: The Table shows the percentage of individuals from each World region of birth that have remitted money or sent goods home at least once in the last year. EU(NMS) refers to countries which joined the European Union after 2004, EU(OMS) refers to countries that where in the EU prior to 2004.

Table 2: Risk Aversion and Probability of Remitting

\begin{tabular}{c|c}
\hline & Percentage remit (\%) \\
\hline Risk Averse & 40 \\
Risk Loving & 27
\end{tabular}

Note: The Table shows the percentage of individuals that have sent money or goods home at least once in the last year. 'Risk Averse' refers to individuals choosing to invest less than EUR 10,000 in the hypothetical lottery, 'Risk Loving' refers to individuals choosing to invest more than EUR 10,000 in the hypothetical lottery. 
Table 3: Probability of Remitting and Risk Preferences

\begin{tabular}{lcccccc}
\hline \hline & $(1)$ & $(2)$ & $(3)$ & $(4)$ & $(5)$ & $(6)$ \\
& Probit & Tobit & Probit & Tobit & Probit & Tobit \\
\hline Risk Averse & $0.193^{* * *}$ & $945.100^{* * *}$ & & & & \\
& $(0.038)$ & $(189.795)$ & & & & \\
Risk Aversion - Alternative 1 & & & $0.126^{* * *}$ & $748.316^{* * *}$ & & \\
& & & $(0.032)$ & $(193.170)$ & & \\
Risk Aversion - Alternative 2 & & & & & $0.168^{* * *}$ & $837.149^{* * *}$ \\
& & & & & $(0.040)$ & $(172.282)$ \\
Temporary Contract & 0.045 & 378.224 & 0.041 & 351.718 & 0.055 & $424.494^{*}$ \\
& $(0.036)$ & $(237.239)$ & $(0.037)$ & $(234.004)$ & $(0.036)$ & $(248.436)$ \\
Return Intention & & & & & & \\
& 0.028 & -183.725 & 0.036 & -148.284 & 0.040 & -121.452 \\
Savings & $(0.030)$ & $(185.558)$ & $(0.030)$ & $(186.932)$ & $(0.029)$ & $(188.301)$ \\
& & & & & & \\
Controls & $0.067^{*}$ & $553.363^{* *}$ & $0.064^{*}$ & $535.002^{* *}$ & $0.070^{*}$ & $570.266^{* *}$ \\
\hline Observations & $(0.038)$ & $(218.544)$ & $(0.038)$ & $(221.321)$ & $(0.037)$ & $(227.721)$ \\
Pseudo $R^{2}$ & & & & & & \\
\hline \hline
\end{tabular}

Marginal effects; Standard errors in parentheses

${ }^{*} p<0.10,{ }^{* *} p<0.05,{ }^{* * *} p<0.01$

Note: The Table reports marginal effects of Probit estimates and Tobit estimates. For the Probit specification the dependent variable is a dummy taking value 1 when individual migrants sent remittances in the year prior to the survey. For the Tobit specification it is the amount remitted in EUR in the year before the survey. Control variables include basic demographics, such as gender, age, years of schooling, religion, marital status, having children, industry of occupation, income, financial distress indicators, and world region of origin. We also include employment contract duration, reported intention to return, number of years in Ireland, partner living in Ireland and Irish partner, as well as employment status of the network member, and the presence of migrant savings. The standard errors in parenthesis are clustered by country of birth. 
Table 4: Remittances and Type of Contract: Extensive and Intensive Margin

\begin{tabular}{lcc}
\hline \hline & $(1)$ & $(2)$ \\
& Probit & Tobit \\
\hline Risk Averse & $0.123^{* * *}$ & $535.217^{* * *}$ \\
& $(0.028)$ & $(160.792)$ \\
Temporary Contract & -0.079 & -366.865 \\
& $(0.056)$ & $(264.313)$ \\
Temporary Contract x Averse & $0.286^{* * *}$ & $1486.060^{* * *}$ \\
& $(0.101)$ & $(398.599)$ \\
Controls & & \\
\hline Observations & Yes & Yes \\
Pseudo $R^{2}$ & 1107 & 1107 \\
\hline \hline
\end{tabular}

Marginal effects; Standard errors in parentheses

${ }^{*} p<0.10,{ }^{* *} p<0.05,{ }^{* * *} p<0.01$

Note: The Table reports marginal effects of Probit estimates and Tobit estimates. For the Probit specification the dependent variable is a dummy taking value 1 when individual migrants sent remittances in the year prior to the survey. For the Tobit specification it is the amount remitted in EUR in the year before the survey. Control variables include basic demographics, such as gender, age, years of schooling, religion, marital status, having children, industry of occupation, income, financial distress indicators, and world region of origin. We also include employment contract duration, reported intention to return, number of years in Ireland, partner living in Ireland and Irish partner, as well as employment status of the network member, and the presence of migrant savings. The standard errors in parentheses are robust and clustered by country of birth. 
Table 5: Remittances and Intention to Return: Intensive and Extensive Margin

\begin{tabular}{lcc}
\hline \hline & $(1)$ & $(2)$ \\
& Probit & Tobit \\
\hline Risk Averse & $0.113^{* *}$ & $500.645^{*}$ \\
& $(0.049)$ & $(292.897)$ \\
Return Intention & -0.034 & $-550.886^{*}$ \\
& $(0.048)$ & $(315.616)$ \\
Return Intention x Averse & $0.150^{* *}$ & $815.319^{* *}$ \\
& $(0.073)$ & $(392.347)$ \\
Controls & & \\
\hline Observations & Yes & Yes \\
Pseudo $R^{2}$ & 1107 & 1107 \\
\hline \hline
\end{tabular}

Marginal effects; Standard errors in parentheses

${ }^{*} p<0.10,{ }^{* *} p<0.05,{ }^{* * *} p<0.01$

Note: The Table reports marginal effects of Probit estimates and Tobit estimates. For the Probit specification the dependent variable is a dummy taking value 1 when individual migrants sent remittances in the year prior to the survey. For the Tobit specification it is the amount remitted in EUR in the year before the survey. 'Return Intention' is a dummy variable for intending to return in the next ten years. Control variables include basic demographics, such as gender, age, years of schooling, religion, marital status, having children, industry of occupation, income, financial distress indicators, and world region of origin. We also include employment contract duration, reported intention to return, number of years in Ireland, partner living in Ireland and Irish partner, as well as employment status of the network member, and the presence of migrant savings. The standard errors in parentheses are robust and clustered by country of birth. 
Table 6: Employment Status of Network Member and Remittances: Intensive and Extensive Margin

\begin{tabular}{lcc}
\hline \hline & $(1)$ & $(2)$ \\
& Probit & Tobit \\
\hline Risk Averse & $0.082^{*}$ & 320.655 \\
& $(0.042)$ & $(346.028)$ \\
Employed Network & -0.058 & -384.834 \\
& $(0.037)$ & $(263.849)$ \\
Employed Network x Averse & $0.163^{* *}$ & $885.987^{*}$ \\
& $(0.071)$ & $(475.482)$ \\
Controls & & \\
\hline Observations & Yes & Yes \\
Pseudo $R^{2}$ & 1107 & 1107 \\
\hline \hline
\end{tabular}

Marginal effects; Standard errors in parentheses

${ }^{*} p<0.10,{ }^{* *} p<0.05,{ }^{* * *} p<0.01$

Note: The Table reports marginal effects of Probit estimates and Tobit estimates. For the Probit specification the dependent variable is a dummy taking value 1 when individual migrants sent remittances in the year prior to the survey. For the Tobit specification it is the amount remitted in EUR in the year before the survey. The probit specification shows the probability of remitting to the main network contact. Control variables include basic demographics, such as gender, age, years of schooling, religion, marital status, having children, industry of occupation, income, financial distress indicators, and world region of origin. We also include employment contract duration, reported intention to return, number of years in Ireland, partner living in Ireland and Irish partner, as well as employment status of the network member, and the presence of migrant savings. The standard errors in parentheses are robust and clustered by country of birth. 
Table 7: Outside Family Networks and Remittances: Intensive and Extensive Margin

\begin{tabular}{|c|c|c|c|c|c|c|}
\hline & $\begin{array}{c}(1) \\
\text { Probit }\end{array}$ & $\begin{array}{c}(2) \\
\text { Probit }\end{array}$ & $\begin{array}{c}(3) \\
\text { Probit }\end{array}$ & $\begin{array}{c}(4) \\
\text { Tobit }\end{array}$ & $\begin{array}{c}(5) \\
\text { Tobit }\end{array}$ & $\begin{array}{c}(6) \\
\text { Tobit }\end{array}$ \\
\hline Risk Averse & $\begin{array}{c}0.261^{* * *} \\
(0.038)\end{array}$ & $\begin{array}{c}0.095 \\
(0.091)\end{array}$ & $\begin{array}{c}0.095 \\
(0.090)\end{array}$ & $\begin{array}{c}1154.186^{* * *} \\
(186.532)\end{array}$ & $\begin{array}{l}-367.578 \\
(320.110)\end{array}$ & $\begin{array}{l}-370.547 \\
(315.020)\end{array}$ \\
\hline Non-Family Net. & $\begin{array}{c}-0.640^{* * *} \\
(0.044)\end{array}$ & $\begin{array}{c}-0.671^{* * *} \\
(0.039)\end{array}$ & $\begin{array}{c}-0.660^{* * *} \\
(0.041)\end{array}$ & $\begin{array}{c}-2660.792^{\text {*** }} \\
(319.400)\end{array}$ & $\begin{array}{c}-3331.606^{* * *} \\
(422.301)\end{array}$ & $\begin{array}{c}-3252.709^{* * *} \\
(407.522)\end{array}$ \\
\hline Employed Network & $\begin{array}{c}0.136^{* * *} \\
(0.028)\end{array}$ & $\begin{array}{c}0.134^{* * *} \\
(0.026)\end{array}$ & $\begin{array}{l}0.083^{* *} \\
(0.033)\end{array}$ & $\begin{array}{c}604.279^{* * *} \\
(179.098)\end{array}$ & $\begin{array}{c}557.781^{* * *} \\
(155.817)\end{array}$ & $\begin{array}{l}307.739^{*} \\
(186.641)\end{array}$ \\
\hline Non-Family Net. x Averse & & $\begin{array}{c}0.194^{*} \\
(0.117)\end{array}$ & $\begin{array}{c}0.067 \\
(0.110)\end{array}$ & & $\begin{array}{c}1976.593^{* * *} \\
(398.611)\end{array}$ & $\begin{array}{c}1320.398^{* * *} \\
(386.823)\end{array}$ \\
\hline Non-Fam. x Averse x Emplyd net. & & & $\begin{array}{l}0.164^{* *} \\
(0.081)\end{array}$ & & & $\begin{array}{l}820.972^{*} \\
(423.459)\end{array}$ \\
\hline Controls & Yes & Yes & Yes & Yes & Yes & Yes \\
\hline Observations & 1107 & 1107 & 1107 & 1107 & 1107 & 1107 \\
\hline Pseudo $R^{2}$ & 0.290 & 0.292 & 0.295 & 0.041 & 0.044 & 0.044 \\
\hline
\end{tabular}

Marginal effects; Standard errors in parentheses

${ }^{*} p<0.10,{ }^{* *} p<0.05,{ }^{* * *} p<0.01$

Note: The Table reports marginal effects of Probit estimates and Tobit estimates. For the Probit specification the dependent variable is a dummy taking value 1 when individual migrants sent remittances in the year prior to the survey. For the Tobit specification it is the amount remitted in EUR in the year before the survey. Control variables include basic demographics, such as gender, age, years of schooling, religion, marital status, having children, industry of occupation, income, financial distress indicators, and world region of origin. We also include employment contract duration, reported intention to return, number of years in Ireland, partner living in Ireland and Irish partner, as well as employment status of the network member, and the presence of migrant savings. The standard errors in parentheses are robust and clustered by country of birth. 